\title{
Aging and chronic administration of serotonin-selective reuptake inhibitor citalopram upregulate Sirt4 gene expression in the preoptic area of male mice
}

\author{
Dutt Way Wong, Tomoko Soga * and Ishwar S. Parhar \\ Brain Research Institute, School of Medicine and Health Sciences, Monash University Malaysia, Selangor, Malaysia
}

\section{OPEN ACCESS}

Edited by:

Shin Murakami,

Touro University California, USA

Reviewed by:

Ruth Luthi-Carter,

University of Leicester, UK

Jie Shen,

Hangzhou Dianzi University, China

Xingguo Liu,

Guangzhou Institutes of Biomedicine

and Health, China

${ }^{\star}$ Correspondence:

Tomoko Soga,

Brain Research Institute, School of

Medicine and Health Sciences,

Monash University Malaysia, Jalan

Lagoon Selatan,

47500 Bandar Sunway, Selangor,

Malaysia

tomoko.soga@monash.edu

Specialty section:

This article was submitted to

Genetics of Aging,

a section of the journal

Frontiers in Genetics

Received: 10 March 2014

Accepted: 21 August 2015

Published: 16 September 2015

Citation:

Wong DW, Soga T and Parhar IS

(2015) Aging and chronic

administration of serotonin-selective

reuptake inhibitor citalopram

upregulate Sirt4 gene expression in

the preoptic area of male mice.

Front. Genet. 6:281.

doi: 10.3389/fgene.2015.00281
Sexual dysfunction and cognitive deficits are markers of the aging process. Mammalian sirtuins (SIRT), encoded by sirt 1-7 genes, are known as aging molecules which are sensitive to serotonin (5-hydroxytryptamine, 5-HT). Whether the 5-HT system regulates SIRT in the preoptic area (POA), which could affect reproduction and cognition has not been examined. Therefore, this study was designed to examine the effects of citalopram (CIT, $10 \mathrm{mg} / \mathrm{kg}$ for 4 weeks), a potent selective-serotonin reuptake inhibitor and aging on SIRT expression in the POA of male mice using real-time PCR and immunocytochemistry. Age-related increases of sirt1, sirt4, sirt5, and sirt7 mRNA levels were observed in the POA of 52 weeks old mice. Furthermore, 4 weeks of chronic CIT treatment started at 8 weeks of age also increased sirt2 and sirt4 mRNA expression in the POA. Moreover, the number of SIRT4 immuno-reactive neurons increased with aging in the medial septum area $(12$ weeks $=1.00 \pm 0.15$ vs. 36 weeks $=1.68 \pm 0.14$ vs. 52 weeks $=1.54 \pm 0.11$, $p<0.05)$. In contrast, the number of sirt4-immunopositive cells did not show a statistically significant change with CIT treatment, suggesting that the increase in sirt4 mRNA levels may occur in cells in which sirt4 is already being expressed. Taken together, these studies suggest that CIT treatment and the process of aging utilize the serotonergic system to up-regulate SIRT4 in the POA as a common pathway to deregulate social cognitive and reproductive functions.

Keywords: serotonin, aging, reproduction, sirtuins, cognition

\section{Introduction}

Aging of the central nervous system deregulates homeostatic mechanisms responsible for sexual behavior (Davidson et al., 1983), feeding (Weindruch et al., 2001), sleep (Nakamura et al., 2011) and cognition (Barrientos et al., 2012). Sexual dysfunction and cognitive loss are prominent markers of the aging process. The preoptic area (POA) is involved in the hypothalamic-pituitary-gonadal (HPG) axis for the control of reproduction (Larsson and Heimer, 1964). Gonadotropin-releasing hormone $(\mathrm{GnRH})$ is a pivotal molecule synthesize by neurons in the POA that regulates the release of gonadotropins ( $\mathrm{LH}$, luteinizing hormone and $\mathrm{FSH}$, follicular stimulating hormone) that are important for reproduction and reproductive behaviors (Tsutsumi and Webster, 2009). The POA including the GnRH neurons receive serotonergic (5-hydroxytrypramine, 5-HT) innervations 
(Van De Kar and Lorens, 1979; Jennes et al., 1982). Pharmacological manipulations and lesions of the serotonergic system has a negative tone on reproduction (Verma et al., 1989; Kondo and Yamanouchi, 1997; Olivier et al., 2011) and cognitive function (Sibille et al., 2007). During aging, sex steroid deprivation shifts the homeostasis of the HPG axis which results in increase circulating LH and GnRH levels (Chakravarti et al., 1976). Furthermore, increases in LH are associated with decline in cognitive performance (Casadesus et al., 2007). Moreover, an age-related decline in the serotonergic system also leads to cognitive dysfunction (Meltzer et al., 1998). The POA is involved in social cognition (Driessen et al., 2014). Hence, to understand the mechanism of reproductive aging and cognitive loss, it is important to examine the serotonergic system in the POA during aging.

The family of seven sirtuin (SIRT) proteins is involved in the aging mechanism, which may include reproductive aging (Duan, 2013). Sirt activity is governed by its coactivator, nicotinamide adenine dinucleotide ( $n a d)$, inhibitor nicotinamide (nam) and the intermediary conversion enzyme nicotinamide mononucleotide adenylyltransferase (nmnat-1) (Denu, 2005). All seven SIRT proteins are expressed in the brain (Dali-Youcef et al., 2007). SIRT proteins are involved in energy balance, reproduction and in brain aging (Duan, 2013). SIRT4 controls glutamate metabolism through glutamate dehydrogenase (Haigis et al., 2006), overexpression of which alters synaptic activity similar to serotonin-depleted models (Michaelis et al., 2011). In addition, serotonin1b (5-HT1b) receptor knockout mice, up-regulate sirt5 in adult male mice, causing early onset of brain aging (Sibille et al., 2007).

Whether the 5-HT system regulates SIRT in the POA, which could affect the HPG axis, reproduction and cognition has not been examined. Treatment with citalopram (CIT), a potent selective-serotonin reuptake inhibitor, shows deficits in sexual behavior in adult mice (Soga et al., 2010) and sexual dysfunction in humans(Montejo et al., 2001), a condition that mimics aging, which has decreased 5-HT synthesis (Hussain and Mitra, 2000). CIT is extremely selective for its transporter, biosynthetic enzymes and receptors and is used pharmacologically to increase endogenous 5-HT levels at the synapse, although, chronic treatment decreases 5-HT synthesis (Moret and Briley, 1996; Bezchlibnyk-Butler et al., 2000; Stenfors et al., 2001). Therefore, this study was design to examine the effect of CIT and aging on sirt mRNA and SIRT expression in the POA of male mice using real-time PCR and immunocytochemistry respectively.

A

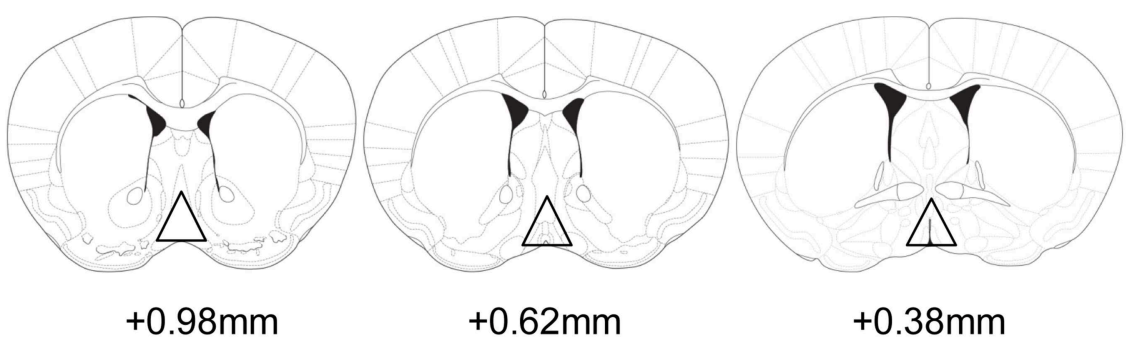

B

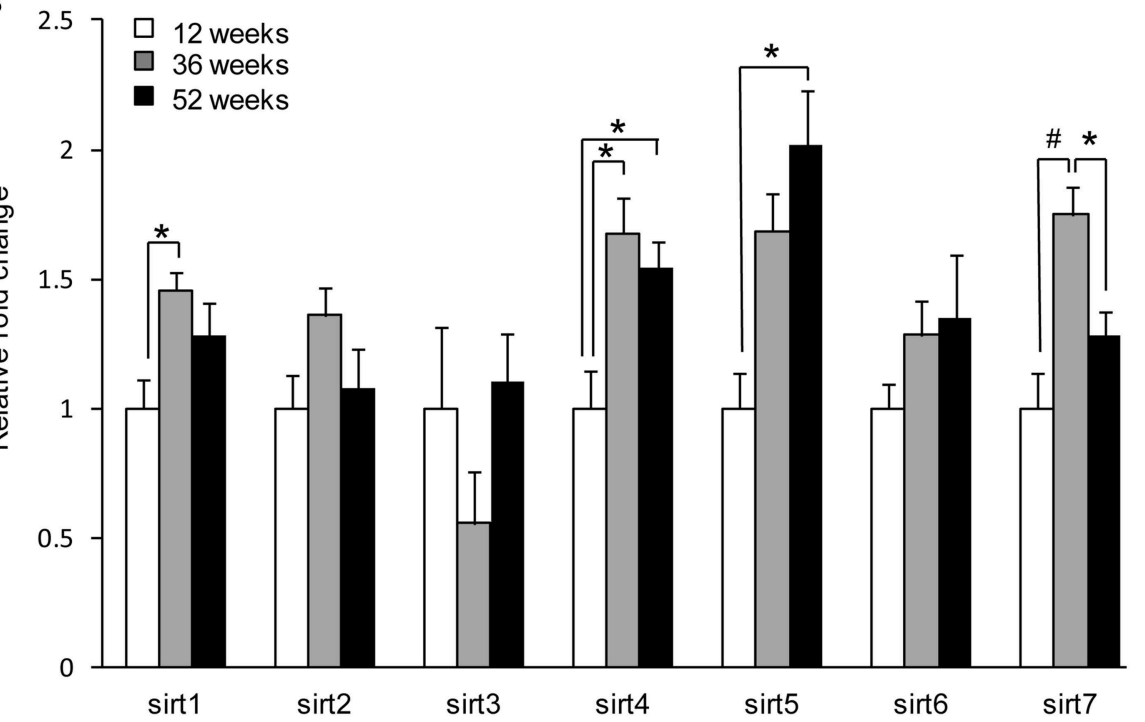

FIGURE 1|Aging induces sirt gene expression in the preoptic area. (A) Representative brain sections depicting areas dissected for gene expression studies in the POA. (B) Quantitative real-time PCR revealed differential sirt expression changes. Data are expressed as mean \pm SEM. Statistical analysis was carried out using one-way analysis of variance (12 weeks control, $n=9 ; 36$ weeks, $n=8 ; 52$ weeks, $n=10$ ). ${ }^{*} P<0.05$ and $\# P<0.01$ vs. control. 


\section{Materials and Methods}

\section{Animals}

Male C57BL/6N mice (CLEA Japan, Inc Tokyo, Japan) aged 12 weeks (weeks) $(n=33), 36$ weeks $(n=8)$, and 52 weeks $(n=16)$ were maintained under standard conditions at the animal facility of the Brain Research Institute, Monash University Malaysia. These conditions include constant temperature $\left(22^{\circ} \mathrm{C}\right)$ and lighting ( $12 \mathrm{~h}$ light/12 $\mathrm{h}$ dark cycle with lights on from 12:00 a.m.) with food and water available ad libitum. All procedures were approved by Animal Ethics Committee of Monash University (SOBSB/MY/2010/45) and were accordance with the Guidelines for the Care and Use of Animals by Monash University.

\section{Chronic Citalopram Treatment}

Mice were administered with CIT $[10 \mathrm{mg} / \mathrm{kg}$ body weight (BW) in $50 \mu \mathrm{l}$, C7861, Sigma-Aldrich, Singapore; $n=15$ ] or $50 \mu \mathrm{l}$ vehicle (distilled water; $n=15$ ) daily at 9 a.m. by intraperitoneal (i.p) injections for 4 weeks beginning at 8 weeks of age until 12 weeks of age. Mice were used for two studies; gene expression study and immunocytochemical study. For the gene expression study [12 weeks (vehicle), $n=9$ and 12 weeks CIT, $n=9$ ] using the POA and compared with gene expressions of intact aged mice ( 36 weeks, $n=8$ and 52 weeks, $n=10$ ). For the immunocytochemical study, the POA of adult mice (12 weeks, $n=6,12$ weeks CIT, $n=6$ ) and mid-age group (52 weeks, $n=$ 6) was used. In this experiment, 52 weeks C57BL/6 male mice represented the reproductive aging model. This strain of mice at 52 weeks begin to exhibit declining male fertility (Fox et al., 2006) characterized by an increase in abnormal spermatozoa leading to ejaculatory disorders (Fabricant and Parkening, 1982), decrease in pheromone production (Wilson and Harrison, 1983), and a decrease in sexual arousal (Bronson and Desjardins, 1982). Additionally, at 52 weeks old these mice begin to experience age-related cognitive decline (Pettan-Brewer et al., 2013).

\section{Real-time PCR Quantification of sirt1-7, nam and nmnat-1 in the POA}

At various ages (12weeks, 12weeks CIT, 36weeks, and 52weeks), animals were deeply anaethesized with an i.p. injection of ketamine xylazine $(4.5 \mathrm{mg} / \mathrm{kg} / \mathrm{BW})$ followed by rapid removal of the brain and snap frozen. The POA (bregma +0.98 to +0.26 , $8-11$ sections/brain) was cut on a cryostat $(60 \mu \mathrm{m} / \mathrm{section})$ and each section further dissected with a sterile blade under naked eye (Figure 1A). Total RNA from these tissues was extracted using TRIzol (Invitrogen, Carlsbad, CA, USA) and transcribed using High Capacity Transcription Kit (Applied Biosystems, Foster City, CA, USA) according to manufacturer's protocols. Quantitative real-time PCR was performed on a ABI 7300 (Applied Biosystems Foster City, CA, USA) using 2X Power SYBR Green PCR mix (Applied Biosystems), and 0.2M primers for sirt1-7, nam, and nmnat-1 (Supplementary Table 1) in a final volume of $10 \mu$ l. The resulting PCR products were validated using an ABI PRISM 310 Genetic Analyzer and Sequence Analysis Software (Applied Biosystems) and ran on a 2.5\% agarose gel with ethidium bromide used for visualization.

\section{SIRT4 Immunocytochemistry}

Male mice at 12 weeks (control, $n=6 ; 12$ weeks CIT, $n=$ 6) and 52 weeks of age (control, $n=6$ ) were anaesthesized with an i.p. injection of ketamine xylazine $(4.5 \mathrm{mg} / \mathrm{kg})$ and perfused transcardially with $4 \%$ paraformaldehyde (PFA) in

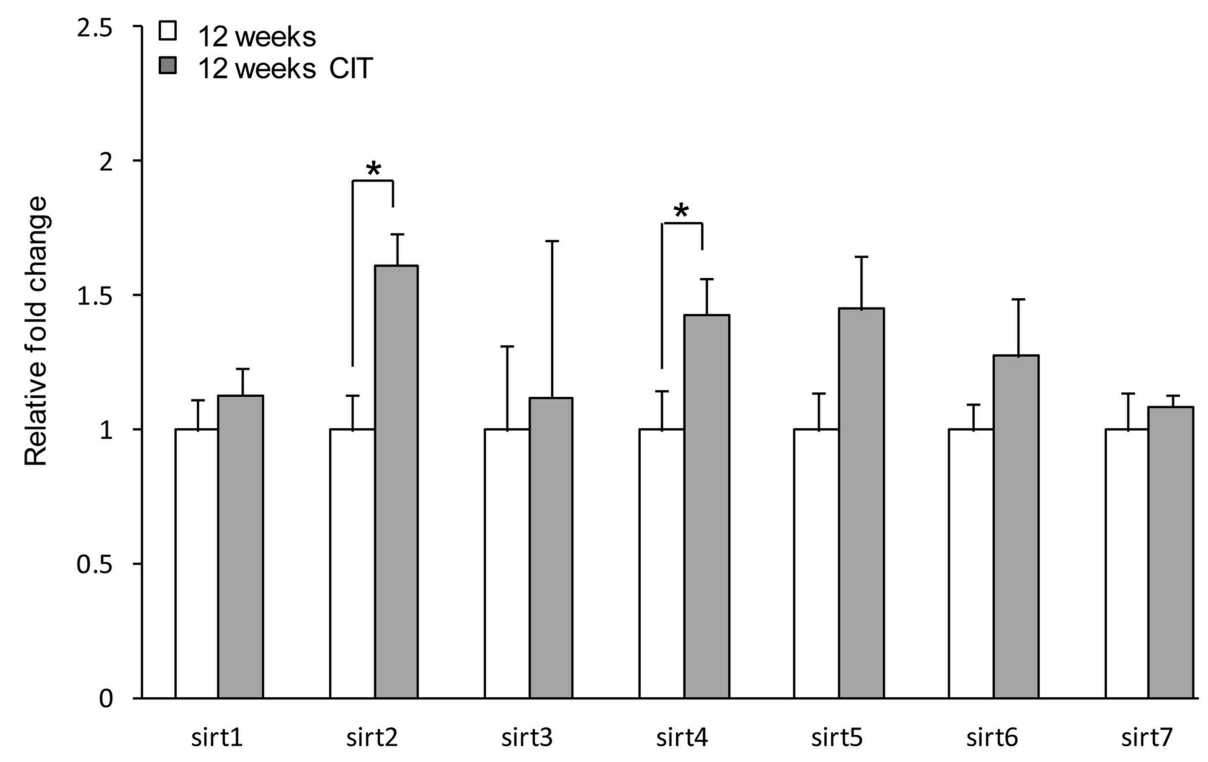

FIGURE 2 | Chronic citalopram (CIT) treatment up-regulates sirt2 and sirt4 in the preoptic area. CIT was administered at $10 \mathrm{mg} / \mathrm{kg} / \mathrm{bodyweight} \mathrm{daily} \mathrm{in} \mathrm{male}$ mice for a duration of 4 weeks leading to relative mRNA changes in sirt2 and sirt4 expression in the POA. There was no difference in sirt3, sirt5, sirt6, or sirt7 mRNA levels in the POA after CIT treatment. Data are expressed as mean \pm SEM. Statistical analysis was carried out using one-way analysis of variance (12 weeks control, $n=9 ; 12$ weeks CIT, $n=9)$. ${ }^{\star} P<0.05$ vs. control. 
$0.1 \mathrm{M}$ phosphate buffer ( $\mathrm{pH} 7.5$ ). The brains were removed, postfixed for $4 \mathrm{~h}$ in $4 \%$ PFA, and cryoprotected in $30 \%$ sucrose overnight. The POA (bregma +0.98 to $+0.26 \mathrm{~mm}$ ) was then sectioned at $30 \mu \mathrm{m}$ in the coronal plane into three equal series. A set of sections was incubated for $20 \mathrm{~min}$ at $60^{\circ} \mathrm{C}$ in sodium citrate $(\mathrm{pH}$ 6) to unmask antigen epitopes. Prior to incubation in blocking solution $(0.25 \%$ bovine serum albumin and $1.0 \%$ Triton $\mathrm{X}$ in $0.1 \mathrm{M}$ PBS) for $1 \mathrm{~h}$ with tissues were washed twice in $0.1 \mathrm{M}$ phosphate buffer saline (PBS) for $10 \mathrm{~min}$ each. Subsequently, the same $0.1 \mathrm{M}$ PBS wash was conducted on tissues prior to every incubation step. Sections were then incubated for $48 \mathrm{~h}$ at $4{ }^{\circ} \mathrm{C}$ in a polyclonal goat antiSIRT4 antibody (ab10140, Abcam, USA) at 1:500 dilution in blocking solution. Next, tissues were incubated with biotinylated rabbit anti-goat (Vector Laboratories, Burlingame, CA, USA) at 1:300 dilution in blocking solution for $1 \mathrm{~h}$. Following this, sections were incubated in avidin-peroxidase (1:100 Vector Laboratories) and immunoreactive signal was observed using nickel-enhanced 3,3'-diaminobenzidine hydrochloride (Sigma). Sections were thoroughly washed in PBS and mounted on SuperFrost Plus slides (Fisher Scientific, Pittsburgh, PA, USA), air-dried, dehydrated in ethanol followed by xylene. Finally, the slides were coverslipped with DPX mounting medium.

\section{Double-label Immunofluorescence}

Coronal POA sections $(30 \mu \mathrm{m})$ from male mice at 12 weeks $(n=3)$ were used for double immunohistochemistry with NeuN or GFAP and antisera to SIRT4 as described above. Tissue sections were incubated in Alexa Fluor 488 Anti-Goat (1:200, A11055, Molecular Probes) for $1 \mathrm{~h}$ and then incubated with either polyclonal rabbit antibody against GFAP (1:500, G9269, Sigma) or mouse monoclonal antibody against NeuN (1:500, MAB377, Millipore-Chemicon, Billerica, MA, USA) for $24 \mathrm{~h}$. Sections incubated with antisera to GFAP were incubated with Alexa Fluor 594 Anti-Rabbit (1:200, A11012, Molecular Probes) while those with antisera to NeuN were incubated with Alexa Fluor 594 Anti-Mouse (1:200, A11005, Molecular Probes). After a final 0.1M PBS wash, sections were mounted on SuperFrost plus slides (Fisher Scientific) and coverslipped with VECTASHIELD mounting medium (H-1000, Vector Laboratories).

\section{Absorption Test and SIRT4 Antibody Specificity}

The SIRT4 antibody employed in this study recognizes amino acids 302-314 at the C-terminal. For testing antibody specificity, two procedures were carried out. Firstly, an absorption test was carried out using intact 12 weeks mice POA sections $(n=$ 3) at 1:500 SIRT4 antisera pre-absorbed overnight with SIRT4 protein (AB23185; amino acids 302-314, $1 \mu \mathrm{g} / \mathrm{ml}$, Abcam) in immunohistochemical procedures. Secondly, the primary SIRT4 antibody was omitted from the primary incubation solution. Both pre-absorbed and omission of SIRT4 antisera did not produce any immunoreactive staining.

\section{SIRT4 Immunoreactive Analysis}

POA sections were viewed using bright-field microscopy (Nikon Eclipse 50i) and images were captured in TIF format (Nikon,
Tokyo, Japan).The distribution of SIRT4 immunoreactivity was mapped throughout the mouse forebrain and brainstem. Cell counts for SIRT4 immunoreactive cells in the POA of 12 weeks, 12 weeks CIT treated, and 52 weeks ( $90 \mu \mathrm{m}$ apart) were carried out using Image Pro Plus (Media Cybernetics Incorporation, Bethesda, USA). The POA consisting of the medial septum (MS), organum vasculosum of the lamina terminalis (OVLT) and the anterior hypothalamic area (AHA) were defined as per unit area of 500,000 pixels, 400,000 pixels, and 50,000 pixels respectively using Image Pro Plus. For each animal, two anatomically matched tissues per area were captured and used for cell counts. Cell counts were carried out by a researcher blind to the treatment and age. A single SIRT4 immunostained cell in a single focal plane was quantified by Image Pro Plus as 120 pixels. Therefore, any clusters of immunoreactive cells quantified by Image Pro Plus were divided by 120 pixels to obtain cell number counts, only immunostained cells with a full size (120 pixels) nuclei were counted in each image of the POA to make adjustments for double counts, in order to obtain true SIRT4 positive cell numbers. Data is expressed as mean number of identifiable SIRT4-immunoreactive cells.

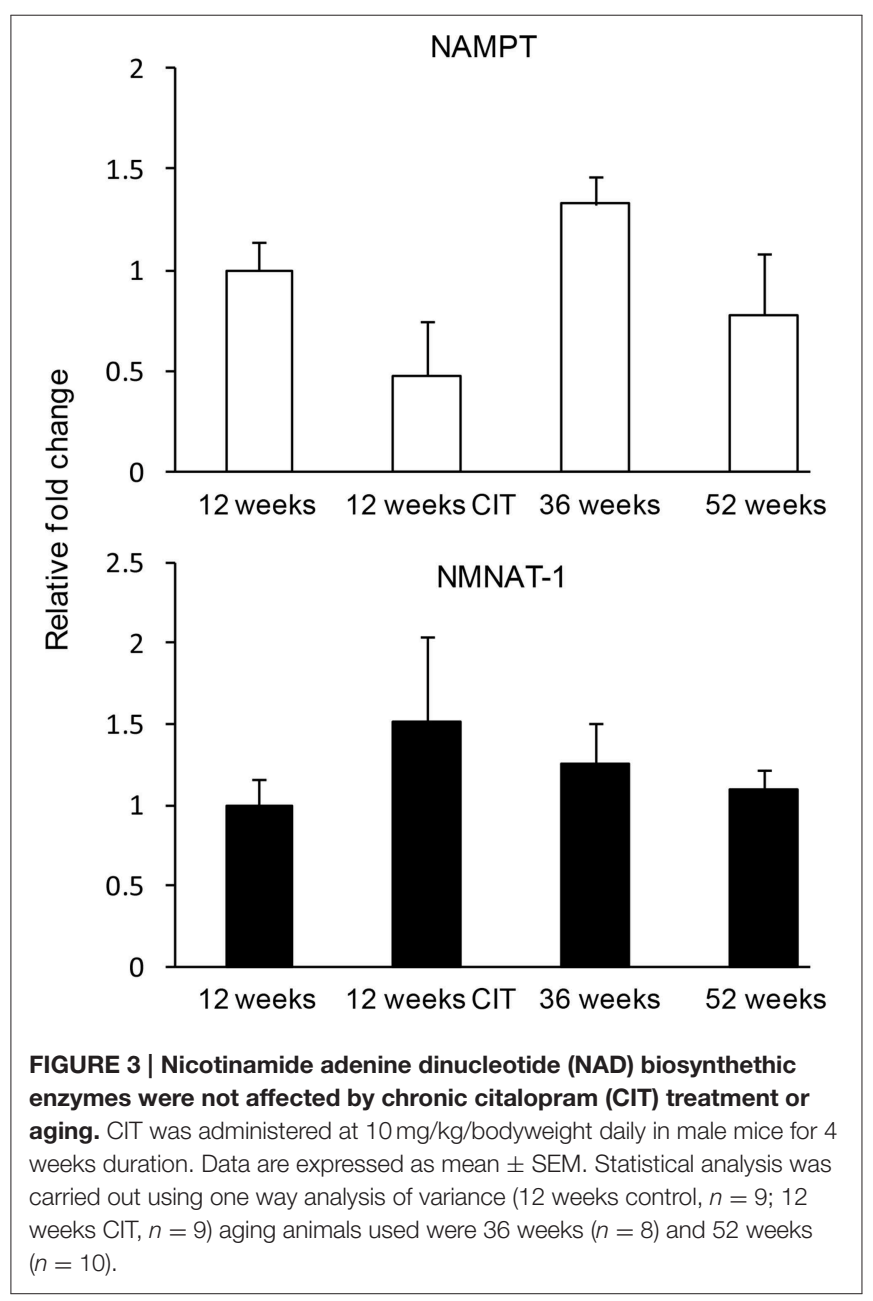




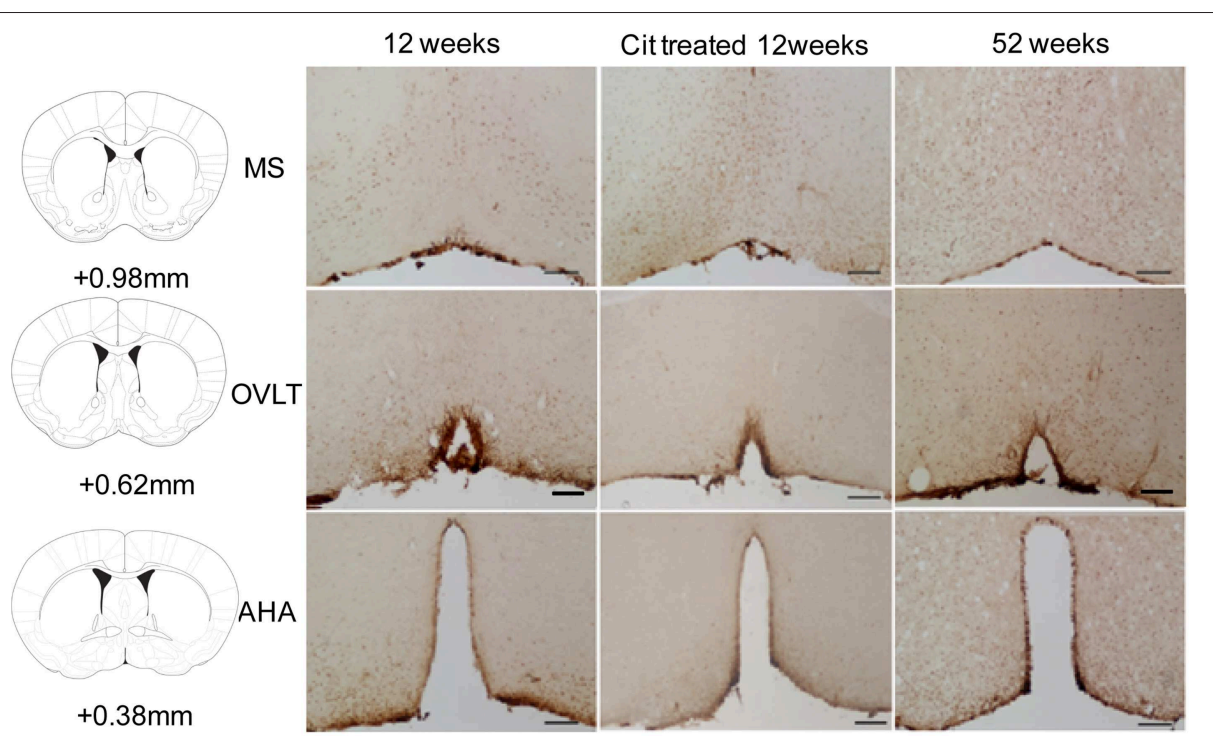

FIGURE 4 | Representative images of SIRT4 immunoreactivity in the medial septum (MS), organum vasculosum of the lamina terminalis (OVLT) and anterior hypothalamic area (AHA) from control, citalopram (CIT) treated and mid-aged samples $\mathbf{( 5 2}$ weeks). Scale bar = $100 \mu \mathrm{m}$.

\section{Double-label Immunofluorescence Analysis}

The co-localization of NeuN or GFAP with SIRT4 immunoreactive cells was viewed with a $20 \mathrm{X}$ objective lens under a fluorescent microscope (Nikon Eclipse 90i, Tokyo, Japan). Sections were viewed using a Texas red filter to observe NeuN and GFAP labeled cells while a fluorescein-isothiocyanate filter was used to observe SIRT4 immunolabeled cells. Images of co-localized cells, SIRT4/NeuN and SIRT4/GFAP, were further captured using a laser scanning confocal microscope (C1si, Nikon) and software (NIS Elements AR v4.0, Nikon). The images were captured at 1024 pixel density using a 20X objective and $3 \mathrm{X}$ digital zoom function at every $1.25 \mu \mathrm{m}$ interval to cover the entire neuronal volume.

\section{Statistical Analysis}

Statistical analysis for the effect of age and treatment (CIT) on sirtuin and NAD was carried out using one-way Analysis of variance (ANOVA) PASW statistic software (Version 17.0 Chicago, IL USA), followed with post-hoc analysis, Tukey's test, for comparison of multiple age groups. The effect of CIT was further analyzed using unpaired Student's $t$-test. Significant main interactions from One-Way ANOVA were further analyzed using Student's $t$-test. Statistical analysis for the effect of age and CIT on SIRT4 protein expression was carried out using Two-Way ANOVA using age and region (MS, OVLT and AHA) as factors followed by $T$-test to determine significance. Data are presented as means \pm SEM. Significant difference was considered when $p<0.05$.

\section{Results}

\section{Effects of Aging on sirt Expression in the POA}

Aging did not alter sirt2, sirt3, and sirt6 gene expression in the POA of male mice. There was an increase in sirt 4 and sirt 5 mRNA expression in the POA during aging [sirt4; 12 weeks $1.00 \pm 0.15$ vs. 36 weeks $1.68 \pm 0.14$ vs. 52 weeks $1.54 \pm 0.11, F_{(2,27)}=7.20$, $p<0.01]$ and [sirt5; $1.00 \pm 0.14$ vs. 36 weeks $1.69 \pm 0.15$ vs. 52 weeks $2.02 \pm 0.21, F_{(2,27)}=10.40, p<0.01$ ] (Figure 1B). Post-hoc analysis revealed an increase in sirt4 (12 weeks vs. 52 weeks; $p<0.05)$ and sirt5 (12 weeks vs. 52 weeks; $p<0.05$ ). sirt1 and sirt7 showed an increase only during 36 week [sirt1; 12 weeks $1.00 \pm 0.11$ vs. 36 weeks $1.46 \pm 0.07$ vs. 52 weeks $1.28 \pm$ $0.12, F_{(2,27)}=4.93, p<0.05$ and sirt7; 12 weeks $1.00 \pm 0.14$ vs. 36 weeks $1.75 \pm 0.11$ vs. 52 weeks $1.28 \pm 0.09, F_{(2,27)}=$ 11.26, $p<0.01$ ] (Figure 1B). Post-hoc analysis for sirt7 revealed a decrease at 52 weeks compared to 36 weeks of age (36 weeks vs. 52 weeks; $p<0.05)$.

\section{Effects of CIT on sirt Expression in the POA}

Chronic CIT treatment induced an increase in sirt2 (12 weeks $1.00 \pm 0.13$ vs. 12 weeks CIT $1.61 \pm 0.12, p<0.05)$ and sirt4 (12 weeks $1.00 \pm 0.15$ vs. 12 weeks CIT $1.43 \pm 0.13, p<0.05$ ) expression in the POA (Figure 2). There was no difference in sirt3, sirt5, sirt6, and sirt7 levels in the POA after CIT treatment (Figure 2).

\section{Effects of Aging and CIT on nampt and nmnat-1 Expression in the POA}

CIT and aging had no effect on nam and nmnat-1 expression in the POA (Figure 3).

\section{Effects of Aging and CIT on SIRT4 Protein in the POA}

SIRT4 immunoreactive cells were observed in the MS, OVLT and AHA regions (Figure 4). We observed SIRT4 protein localized mainly in neurons compared to glial cells in the POA (Figure 5A). SIRT4 co-localization with glial cells were observed in areas close to the third ventricle of the preoptic area whereas 


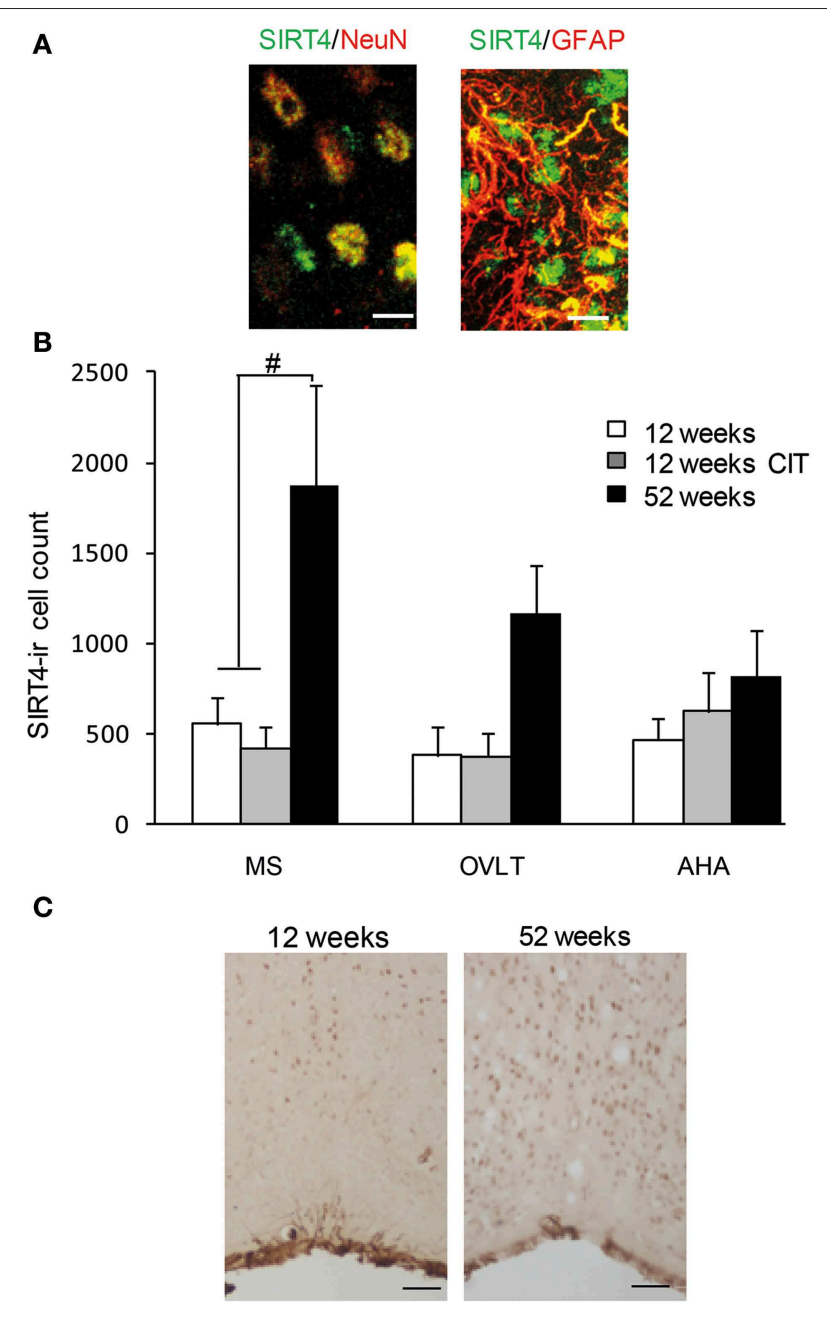

FIGURE 5 | Aging but not citalopram (CIT) induced SIRT4 immunoreactive cells in the medial septum (MS). (A) SIRT4 in the POA was observed to be highly co-localized with neuronal nuclei (NeuN) compared to glial fibrillary acidic protein (GFAP) Scale bar $=10 \mu \mathrm{m}$. (B) SIRT4 immunoreactive cell counts revealed up-regulation of SIRT4 during aging in the MS but not in the organum vasculosum of the lamina terminalis (OVLT) and anterior hypothalamic area (AHA). However, CIT treatment did not alter any SIRT4 immunoreactive cell counts. (C) High magnification image of SIRT4 staining in MS of 12 weeks and 52 weeks. Scale bar $=50 \mu \mathrm{m}$. Data are expressed as mean \pm SEM. Statistical analysis was carried out using analysis of variance, $\# P<0.01$ vs. control.

the vast majority of SIRT4 immunoreactivity was observed in neurons. There was no immunostaining when the antibody was preadsorbed with its corresponding antigen or when the antibody was excluded.

There was an increase in SIRT4 immunoreactive cell counts in the MS of 52weeks aging male mice (12 weeks $421 \pm$ 116, 12 weeks CIT $559 \pm 146,52$ weeks $1521 \pm 306)$ [Age effect in the MS, $\left.F_{(1,16)}=16.98, p<0.01\right]$ and $T$ test revealed that SIRT4 immunoreactivity at 52 weeks was higher than 12 weeks $(p<0.05)$ and 12 weeks CIT treated mice $(p<0.01)$ (Figures 5B,C). CIT treatment did not alter SIRT4 immunoreactivity in the MS. Age and CIT treatment did not alter SIRT4 expression in the OVLT and AHA (Figure 5B).

\section{Discussion}

In this study, we observed an age-related up-regulation of sirt1, sirt4, sirt5, and sirt7 gene expression in the POA. The expression patterns of sirt1, sirt4, sirt5, and sirt7 gene were different at 36 and 52 weeks, which suggest that different regulatory factors might be involved in their control. Higher levels of sirt4 and sirt5 mRNA at 52 weeks may be linked with a decrease in 5HT (Hussain and Mitra, 2000) and a decrease in testosterone levels (Eleftheriou and Lucas, 1974; De Marte and Enesco, 1986) which are observed during the aging process. In contrast to sirt4 and sirt5 expression pattern in the POA, the expression level of sirt7 was higher in 36 weeks than in 52 weeks old animals. This could be due to an overall decrease in transcription activity in the brain at 52 weeks or due to hypothalamic neurodegeneration that begins at 36 weeks (Bourre and Piciotti, 1992). Since sirt1 is an age induced gene (Duan, 2013), the increase expression of sirt1 in the POA of 36 weeks old animals was not unexpected. Sirt 1 gene expression may be regulated by site-specific modulation in the brain. As sirt 1 gene is a regulator of metabolic functions, centrally through the hypothalamus (Duan, 2013), up-regulation of sirtl gene expression may be due to metabolic changes at 36 weeks in the POA.

CIT treatment up-regulated only sirt2 and sir4 gene in the POA. Sirt1 remained unchanged following CIT treatment as it does not respond to SSRI-class of antidepressant (Kishi et al., 2011). This suggests that the effect of CIT on sirt1 might involve factors aside from 5-HT that change in the male HPG axis during aging (Veldhuis, 2008). CIT treatment may affect sirt2 gene through 5-HT signaling in the POA, since sirt2 gene upregulation is also seen in patients during remission state of depression (Abe et al., 2011). On the other hand, sirt4 gene expression is regulated by age and CIT in the POA. A decrease in 5-HT during aging (Hussain and Mitra, 2000) has been linked with neurodegenerative diseases (Glorioso et al., 2011), decreased gonadotropin release and cognitive loss (Alzheimer's disease) (Simpkins et al., 1977; Meltzer et al., 1998). Antidepressants like CIT and fluvoxamine cause sexual dysfunction in rodents (Montejo et al., 2001; Soga et al., 2010), and human (Waldinger et al., 2001). Recent studies have shown that chronic SSRI treatment could decrease 5-HT content and signaling in the brain (Delgado et al., 1990; Hervás and Artigas, 1998), rather than simply facilitating synaptic 5-HT availability (de Jong et al., 2006; Geddes et al., 2015). Therefore, age-related and CIT induced sexual dysfunction and cognitive loss due to the decline in 5-HT in the POA may be mediated by an up-regulation of sirt4 gene expression.

We speculate that the up-regulation of sirt4 gene expression in the POA might occur through one or several potential mechanisms, such as: (1) the blockade of 5-HT uptake by chronic CIT treatment could decrease presynaptic 5-HT content or desensitize postsynaptic 5-HT receptors; (2) the aging process might be associated with a decrease in 5-HT synthesis or a decline in postsynaptic 5-HT receptors (Figure 6). According to 


\section{POA}

A
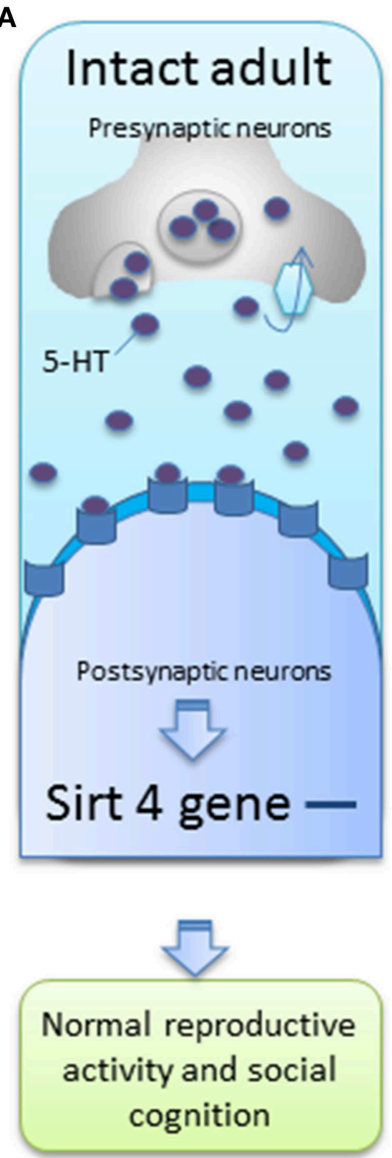

B

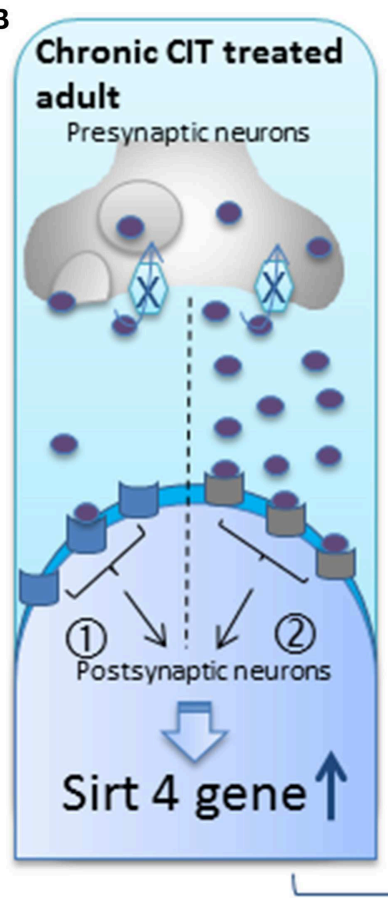

C

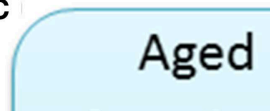

Presynaptic neurons
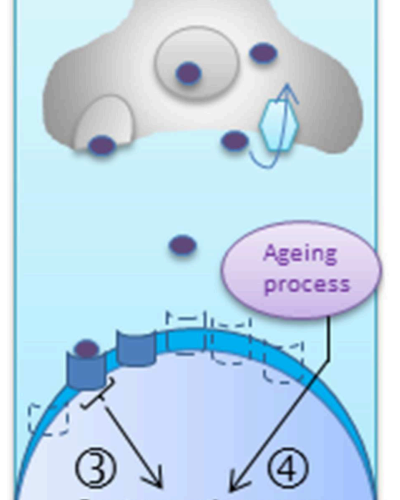

Postsynaptic neurons

Sirt 4 gene $\uparrow$

\section{Decline reproductive activity and social cognition}

FIGURE 6 | A hypothetical diagram of sirt4 gene regulation by serotonin (5-HT) in the preoptic area (POA) of intact adult, chronic citalopram (CIT) treated adult and aged animals. (A) In the intact adult, sirt4 gene expression levels do not change; (B) in the chronic CIT treated adult, the inhibition of 5-HT re-uptake results in decreased presynaptic 5-HT content (pathway (1) or desensitization of postsynaptic receptors that could subsequently be less activated in the presence of normal, or even increased, synaptic 5-HT concentrations (pathway (2)), either of which can result in decreased 5-HT neurotransmission and increased sirt4 gene expression; (C) in aged animals, the serotonergic system may be impaired by decreased 5-HT synthesis (pathway (3) or a decrease in postsynaptic 5-HT receptors (dotted receptor) (pathway (4) to explain sirt4 upregulation, or an unknown age related effect could increase sirt4 gene expression. These 5-HT signaling

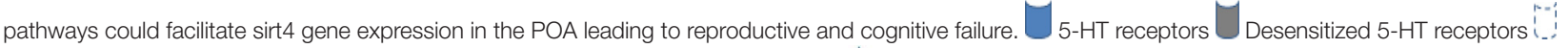
Decrease 5-HT receptors $\bigcup_{5-H T \text { transporter }} \hat{\jmath}_{\text {re-uptake }} X_{\text {Inhibition of re-uptake }} \uparrow_{\text {increase }}$ No change in gene expression, (1) decrease 5-HT neurotransmission, (2) desensitized receptor, (3) decrease 5-HT neurotransmission, (4)unknown age-related factors could activate sirt4 gene expression.

our model, any of these events could explain a change in sirt4 expression associated with a decrease in serotonergic tone.

The localization of SIRT4 primarily in adult neurons is similar to other members of the SIRT family; SIRT1 and SIRT2 in neurons (Houtkooper et al., 2012). The roles of SIRT1, 2 and 4 in neuronal and glial development have been reported (Prozorovski et al., 2008; Park et al., 2012; Komlos et al., 2013). SIRT4 might function in tandem with other SIRT during early development of glial cells and aging of neurons in the POA. Unlike the increase in sirt4 mRNA, our failure to observe an increase in the number of SIRT4 immunostained cells in the POA following CIT treatment could be due to the methodology used to detect protein levels. Although, immunohistochemistry is an accepted semi-quantitative measure of protein levels; a subtle change in protein levels within cells could go undetected using immunocytochemistry and thereby result in unaltered SIRT4 cell numbers.

The POA is involved in social cognitive functions such as paternal behavior, social recognition and reproductive behavior (Ferguson et al., 2002). An age-related decline in cognitive and reproductive functions (Meltzer et al., 1998) might be associated with decline in the serotonergic system. The POA is known to project to brain regions important for cognitive functions such as the dorsal raphe that harbors 5-HT neurons and the 
hippocampus (Sava and Markus, 2008). This suggests that the anatomical and functional connection between the POA and the hippocampus and the dorsal raphe might be involved in age-related cognitive impairment. Inversely, 5-HT neurons are known to project to $\mathrm{GnRH}$ neurons in the POA (Jennes et al., 1982). A decrease in 5-HT during aging could decrease GnRH levels through the activation of sirt, which could cause a decrease in $\mathrm{LH}$ receptors and $\mathrm{GnRH}$ receptors in the hippocampus, resulting in deregulation of the social cognitive functions.

Hence, we suggest that the age-related and CIT-induced activation of sirt4 gene expression, might be initiated by the decline in 5-HT in the POA which leads to reproductive dysfunction and cognitive deficits.

\section{References}

Abe, N., Uchida, S., Otsuki, K., Hobara, T., Yamagata, H., Higuchi, F., et al. (2011). Altered sirtuin deacetylase gene expression in patients with a mood disorder. J. Psychiatr. Res. 45, 1106-1112. doi: 10.1016/j.jpsychires.2011.01.016

Barrientos, R. M., Frank, M. G., Watkins, L. R., and Maier, S. F. (2012). Aging-related changes in neuroimmune-endocrine function: implications for hippocampal-dependent cognition. Horm. Behav. 62, 219-227. doi: 10.1016/j.yhbeh.2012.02.010

Bezchlibnyk-Butler, K., Aleksic, I., and Kennedy, S. H. (2000). Citalopram-a review of pharmacological and clinical effects. J. Psychiatry Neurosci. 25, 241-254.

Bourre, J. M., and Piciotti, M. (1992). Delta-6 desaturation of alpha-linolenic acid in brain and liver during development and aging in the mouse. Neurosci. Lett. 141, 65-68. doi: 10.1016/0304-3940(92)90335-5

Bronson, F. H., and Desjardins, C. (1982). Endocrine responses to sexual arousal in male mice. Endocrinology 111, 1286-1291. doi: 10.1210/endo-1114-1286

Casadesus, G., Milliken, E. L., Webber, K. M., Bowen, R. L., Lei, Z., Rao, C. V., et al. (2007). Increases in luteinizing hormone are associated with declines in cognitive performance. Mol. Cell. Endocrinol. 269, 107-111. doi: 10.1016/j.mce.2006.06.013

Chakravarti, S., Collins, W. P., Forecast, J. D., Newton, J. R., Oram, D. H., and Studd, J. W. (1976). Hormonal profiles after the menopause. Br. Med. J. 2, 784-787. doi: 10.1136/bmj.2.6039.784

Dali-Youcef, N., Lagouge, M., Froelich, S., Koehl, C., Schoonjans, K., and Auwerx, J. (2007). Sirtuins: the 'magnificent seven', function, metabolism and longevity. Ann. Med. 39, 335-345. doi: 10.1080/07853890701408194

Davidson, J. M., Chen, J. J., Crapo, L., Gray, G. D., Greenleaf, W. J., and Catania, J. A. (1983). Hormonal changes and sexual function in aging men. J. Clin. Endocrinol. Metab. 57, 71-77. doi: 10.1210/jcem-57-1-71

de Jong, T. R., Snaphaan, L. J., Pattij, T., Veening, J. G., Waldinger, M. D., Cools, A. R., et al. (2006). Effects of chronic treatment with fluvoxamine and paroxetine during adolescence on serotonin-related behavior in adult male rats. Eur. Neuropsychopharmacol. 16, 39-48. doi: 10.1016/j.euroneuro.2005.06.004

Delgado, P. L., Charney, D. S., Price, L. H., Aghajanian, G. K., Landis, H., and Heninger, G. R. (1990). Serotonin function and the mechanism of antidepressant action. Reversal of antidepressant-induced remission by rapid depletion of plasma tryptophan. Arch. Gen. Psychiatry 47, 411-418. doi: 10.1001/archpsyc. 1990.01810170011002

De Marte, M. L., and Enesco, H. E. (1986). Influence of low tryptophan diet on survival and organ growth in mice. Mech. Ageing Dev. 36, 161-171. doi: 10.1016/0047-6374(86)90017-5

Denu, J. M. (2005). Vitamin B3 and sirtuin function. Trends Biochem. Sci. 30, 479-483. doi: 10.1016/j.tibs.2005.07.004

Driessen, T. M., Eisinger, B. E., Zhao, C., Stevenson, S. A., Saul, M. C., and Gammie, S. C. (2014). Genes showing altered expression in the medial preoptic area in the highly social maternal phenotype are related to autism and other disorders with social deficits. BMC Neurosci. 15:11. doi: 10.1186/1471-2202-15-11

\section{Acknowledgments}

Grant sponsor: (1) TS-10-01 (to TS, ISP), Monash University Malaysia. (2) FRGS/1/2011/ST/MUSM/02/1 (TS, IP), Ministry of Higher Education (MOHE), Malaysia.

\section{Supplementary Material}

The Supplementary Material for this article can be found online at: http://journal.frontiersin.org/article/10.3389/fgene. 2015.00281

Supplementary Table 1 | Sequences of primers used for real-time PCR.

Duan, W. (2013). Sirtuins: from metabolic regulation to brain aging. Front. Aging Neurosci. 5:36. doi: 10.3389/fnagi.2013.00036

Eleftheriou, B. E., and Lucas, L. A. (1974). Age-related changes in testes, seminal vesicles and plasma testosterone levels in male mice. Gerontologia 20, 231-238. doi: 10.1159/000212019

Fabricant, J. D., and Parkening, T. A. (1982). Sperm morphology and cytogenetic studies in ageing C57BL/6 mice. J. Reprod. Fertil. 66, 485-489. doi: 10.1530/jrf.0.0660485

Ferguson, J. N., Young, L. J., and Insel, T. R. (2002). The neuroendocrine basis of social recognition. Front. Neuroendocrinol. 23, 200-224. doi: 10.1006/frne.2002.0229. doi: 10.1006/frne.2002.0229

Fox, J. G., Barthold, S., Davisson, M., Newcomer, C. E., Quimby, F. W., and Smith, A. (2006). The Mouse in Biomedical Research: Normative Biology, Husbandry, and Models. Amsterdam: Elsevier Science.

Geddes, S. D., Assadzada, S., Sokolovski, A., Bergeron, R., Haj-Dahmane, S., and Béïque, J. C. (2015).Time- dependent modulation of glutamate synapses onto 5HT neurons by antidepressant treatment. Neuropharmacology 5, 130-143. doi: 10.1016/j.neuropharm.2015.02.027

Glorioso, C., Oh, S., Douillard, G. G., and Sibille, E. (2011). Brain molecular aging, promotion of neurological disease and modulation by Sirtuin 5 longevity gene polymorphism. Neurobiol. Dis. 41, 279-290. doi: 10.1016/j.nbd.2010.09.016

Haigis, M. C., Mostoslavsky, R., Haigis, K. M., Fahie, K., Christodoulou, D. C., Murphy, A. J., et al. (2006). SIRT4 inhibits glutamate dehydrogenase and opposes the effects of calorie restriction in pancreatic beta cells. Cell 126, 941-954. doi: 10.1016/j.cell.2006.06.057

Hervás, I., and Artigas, F. (1998). Effect of fluoxetine on extracellular 5hydroxytryptamine in rat brain. Role of 5-HT autoreceptors. Eur. J. Pharmacol. 358, 9-18 doi: 10.1016/S0014-2999(98)00579-2

Houtkooper, R. H., Pirinen, E., and Auwerx, J. (2012). Sirtuins as regulators of metabolism and healthspan. Nat. Rev. Mol. Cell Biol. 13, 225-238. doi: $10.1038 / \mathrm{nrm} 3293$

Hussain, A. M., and Mitra, A. K. (2000). Effect of aging on tryptophan hydroxylase in rat brain: implications on serotonin level. Drug Metabol. Dispos. 28, $1038-1042$.

Jennes, L., Beckman, W. C., Stumpf, W. E., and Grzanna, R. (1982). Anatomical relationships of serotoninergic and noradrenalinergic projections with the GnRH system in septum and hypothalamus. Exp. Brain Res. 46, 331-338. doi: 10.1007/BF00238628

Kishi, T., Fukuo, Y., Kitajima, T., Okochi, T., Yamanouchi, Y., Kinoshita, Y., et al. (2011). SIRT1 gene, schizophrenia and bipolar disorder in the Japanese population: an association study. Genes Brain Behav. 10, 257-263. doi: 10.1111/j.1601-183X.2010.00661.X

Komlos, D., Mann, K. D., Zhuo, Y., Ricupero, C. L., Hart, R. P., Liu, A. Y., et al. (2013). Glutamate dehydrogenase 1 and SIRT4 regulate glial development. Glia 61, 394-408. doi: 10.1002/glia.22442

Kondo, Y., and Yamanouchi, K. (1997). Potentiation of ejaculatory activity by median raphe nucleus lesions in male rats: effect of p-chlorophenylalanine. Endocr. J. 44, 873-879. doi: 10.1507/endocrj.44.873 
Larsson, K., and Heimer, L. (1964). Mating behaviour of male rats after lesions in the preoptic area. Nature 202, 413-414. doi: 10.1038/202413a0

Meltzer, C. C., Smith, G., Dekosky, S. T., Pollock, B. G., Mathis, C. A., Moore, R. Y., et al. (1998). Serotonin in aging, late-life depression, and Alzheimer's disease: the emerging role of functional imaging. Neuropsychopharmacology 18, 407-430. doi: 10.1016/S0893-133X(97)00194-2

Michaelis, E. K., Wang, X., Pal, R., Bao, X., Hascup, K. N., Wang, Y., et al. (2011). Neuronal Glud1 (glutamate dehydrogenase 1) over-expressing mice: increased glutamate formation and synaptic release, loss of synaptic activity, and adaptive changes in genomic expression. Neurochem. Int. 59, 473-481. doi: 10.1016/j.neuint.2011.03.003

Montejo, A. L., Llorca, G., Izquierdo, J. A., and Rico-Villademoros, F. (2001). Incidence of sexual dysfunction associated with antidepressant agents: a prospective multicenter study of 1022 outpatients. Spanish Working Group for the Study of Psychotropic-Related Sexual Dysfunction. J. Clin. Psychiatry 62 (Suppl. 3), 10-21.

Moret, C., and Briley, M. (1996). Effects of acute and repeated administration of citalopram on extracellular levels of serotonin in rat brain. Eur. J. Pharmacol. 295, 189-197. doi: 10.1016/0014-2999(95)00646-X

Nakamura, T. J., Nakamura, W., Yamazaki, S., Kudo, T., Cutler, T., Colwell, C. S., et al. (2011). Age-related decline in circadian output. J. Neurosci. 31, 10201-10205. doi: 10.1523/JNEUROSCI.0451-11.2011

Olivier, B., Chan, J. S., Snoeren, E. M., Olivier, J. D., Veening, J. G., Vinkers, C. H., et al. (2011). Differences in sexual behaviour in male and female rodents: role of serotonin. Curr. Top. Behav. Neurosci. 8, 15-36. doi: 10.1007/7854_2010_116

Park, S. H., Zhu, Y., Ozden, O., Kim, H. S., Jiang, H., Deng, C. X., et al. (2012). SIRT2 is a tumor suppressor that connects aging, acetylome, cell cycle signaling, and carcinogenesis. Transl. Cancer Res. 1, 15-21.

Pettan-Brewer, C., Touch, D. V., Wiley, J. C., Hopkins, H. C., Rabinovitch, P. S., and Ladiges, W. C. (2013). A novel radial water tread maze tracks agerelated cognitive decline in mice. Pathobiol. Aging Age Relat. Dis. 3:20679. doi: 10.3402/pba.v3i0.20679

Prozorovski, T., Schulze-Topphoff, U., Glumm, R., Baumgart, J., Schröter, F., Ninnemann, O., et al. (2008). Sirt1 contributes critically to the redox-dependent fate of neural progenitors. Nat. Cell Biol. 10, 385-394. doi: 10.1038/ncb1700

Sava, S., and Markus, E. J. (2008). Activation of the medial septum reverses agerelated hippocampal encoding deficits: a place field analysis. J. Neurosci. 28, 1841-1853. doi: 10.1523/JNEUROSCI.4629-07.2008

Sibille, E., Su, J., Leman, S., Le Guisquet, A. M., Ibarguen-Vargas, Y., JoeyenWaldorf, J., et al. (2007). Lack of serotonin1B receptor expression leads to agerelated motor dysfunction, early onset of brain molecular aging and reduced longevity. Mol. Psychiatry 12, 1042-1056, 1975. doi: 10.1038/sj.mp.4001990

Simpkins, J. W., Mueller, G. P., Huang, H. H., and Meites, J. (1977). Evidence for depressed catecholamine and enhanced serotonin metabolism in aging male rats: posssible relation to gondotropin secretion. Endocrinology 100, 1672-1678. doi: 10.1210/endo-100-6-1672

Soga, T., Wong, D. W., Clarke, I. J., and Parhar, I. S. (2010). Citalopram (antidepressant) administration causes sexual dysfunction in male mice through RF-amide related peptide in the dorsomedial hypothalamus. Neuropharmacology 59, 77-85. doi: 10.1016/j.neuropharm.2010. 03.018

Stenfors, C., Yu, H., and Ross, S. B. (2001). Pharmacological characterisation of the decrease in 5-HT synthesis in the mouse brain evoked by the selective serotonin re-uptake inhibitor citalopram. Naunyn. Schmiedebergs. Arch. Pharmacol. 363, 222-232. doi: 10.1007/s002100000347

Tsutsumi, R., and Webster, N. J. (2009). GnRH pulsatility, the pituitary response and reproductive dysfunction. Endocr. J. 56, 729-737. doi: 10.1507/endocrj.K09E-185

Van De Kar, L. D., and Lorens, S. A. (1979). Differential serotonergic innervation of individual hypothalamic nuclei and other forebrain regions by the dorsal and median midbrain raphe nuclei. Brain Res. 162, 45-54. doi: 10.1016/00068993(79)90754-6

Veldhuis, J. (2008). Aging and hormones of the hypothalamo-pituitary axis: gonadotropic axis in men and somatotropic axes in men and women. Ageing Res. Rev. 7, 189-208. doi: 10.1016/j.arr.2007.12.005

Verma, S., Chhina, G. S., Mohan Kumar, V., and Singh, B. (1989). Inhibition of male sexual behavior by serotonin application in the medial preoptic area. Physiol. Behav. 46, 327-330. doi: 10.1016/0031-9384(89)90275-8

Waldinger, M. D., Zwinderman, A. H., and Olivier, B. (2001). SSRIs and ejaculation: a double-blind, randomized, fixed-dose study with paroxetine and citalopram. J. Clin. Psychopharmacol. 21, 556-560. doi: 10.1097/00004714200112000-00003

Weindruch, R., Kayo, T., Lee, C. K., and Prolla, T. A. (2001). Microarray profiling of gene expression in aging and its alteration by caloric restriction in mice. J. Nutr. 131, 918S-923S.

Wilson, M. C., and Harrison, D. E. (1983). Decline in male mouse pheromone with age. Biol. Reprod. 29, 81-86. doi: 10.1095/biolreprod29.1.81

Conflict of Interest Statement: The authors declare that the research was conducted in the absence of any commercial or financial relationships that could be construed as a potential conflict of interest.

Copyright (C) 2015 Wong, Soga and Parhar. This is an open-access article distributed under the terms of the Creative Commons Attribution License (CC BY). The use, distribution or reproduction in other forums is permitted, provided the original author(s) or licensor are credited and that the original publication in this journal is cited, in accordance with accepted academic practice. No use, distribution or reproduction is permitted which does not comply with these terms. 